\title{
EL CONCEPTO DE EXPLOTACION COMO UNO DE LOS ELEMENTOS DETERMINANTES DE LA NO SUJECION AL ARBITRIO SOBRE EL INCREMENTO DEL VALOR DE LOS TERRENOS
}

$336.2: 352.72$

\author{
por \\ José-Enrique Rebés Solé \\ Abogado. Letrado consistorial. Jefe Adjunto del Servicio Contencioso \\ del Excmo. Ayuntamiento de Barcelona
}

SUMARIO: I. INTRODUCCION.-II. LA SUJECION AL ARBITRIO COMO REGLA GENERAL.-III. LOS SUPUESTOS DE NO SUJECION.-IV. TERRENOS AFECTOS A UNA EXPLOTACION AGRICOLA, FORESTAL, GANADERA O MINERA: 1. Dificultades PARA la DETERMINACIÓN DEL CONCEPTO DE EXPLOTACIÓN. 2.' APROXIMACIÓN JURISPRUDENCIAL AL CONCEPTO TRADICIONAL DE EXPLOTACIÓN. 3. DELIMITACIÓN aCtUAL POR EL TRIBUNAL SUPREMO DEL CONCEPTO DE EXPLOTACIÓN. 4. EXAMEN CRÍTICO DE LA INTERPRETACIÓN FORMULADA POR EL TRIBUNAL SUPREM O.-V. REFERENCIAS A LA ELABORACION DOCTRINAL DEL CONCEPTO DE EXPLOTACION (AGRICOLA).-VI. MANTENIMIENTO DE LA INDETERMINACION LEGAL DEL CONCEPTO. POSIBLES PROPUESTAS.-VII. CONCLUSIONES.

\section{INTRODUCCION}

El presente trabajo va destinado a examinar en qué manera la afectación de un terreno a una explotación (agrícola, forestal, ganadera o minera) constituye uno de los elementos que deben concurrir para que pueda invocarse con éxito la no sujeción al arbitrio 
sobre el incremento del valor de los terrenos, comúnmente denominado arbitrio de "plusvalía».

El interés del mismo, si es que lo tiene, radica, fundamentalmente, en los siguientes aspectos: primero, por la constante permanencia en nuestra legislación de las citadas afectaciones como elemento delimitador de carácter negativo del ámbito del arbitrio, y cuya configuración legal la encontramos formulada, prácticamente, en la misma forma que en la actualidad, desde la misma creación del arbitrio sobre el incremento del valor de los terrenos (1); segunaio, por el extraordinario interés que ha despertado desde siempre para el contribuyente, pues ha visto -y en muchísimas ocasiones ha conseguido- que la alegación de este tipo de "afectaciones-explotaciones" daba lugar (por imperativo de la normativa tributaria), si se acreditaba debidamente, a la declaración de la no sujeción al arbitrio y, por consiguiente, a la desaparición total de la cuota; tercero, porque esta cuestión es la que ha planteado mayor número de reclamaciones no sólo en vía administrativa (2), sino, especialmente, en la jurisdiccional, dando lugar a una copiosísima e interesante doctrina jurisprudencial, que ha ido introduciendo un notable cambio en la apreciación de las circunstancias que deben concurrir para que la alegación de las citadas afectaciones tengan algún éxito; y, finalmente, cuarto, que ni la Ley 41/1975, de 19 de noviembre, reguladora de las Bases del Estatuto de Régimen local, ni el Real Decreto 3.250/1976, de 30 de diciembre, que desarrolló de la citada Ley las Bases relativas a «ingresos de las Corporaciones locales», no han introducido, en este aspecto, variación sustancial alguna. Por tanto, el planteamiento temático y la doctrina jurisprudencial mantienen su rigurosa actualidad.

(1) En efecto, desde que el Real Decreto de 13 de marzo de 1919 creó el gravamen sobre el aumento del valor de los terrenos, su configuración -salvo pequeñas variantes (la más importante para el supuesto que contemplamos la intro. dujo el artículo 422, en relación con el artículo 386, del Estatuto municipal, al que ya aludiremos) - ha ido superando todas las modificaciones $-\mathrm{y}$ no han sido pocas- que en materia de Haciendas locales se han producido a lo largo de todo nuestro siglo.

(2) En distintos Ayuntamientos hemos tenido ocasión de comprobar cómo, en efecto, las reclamaciones por el arbitrio sobre el incremento, del.valor de los terrenos en las que se alega la explotación agrícola o forestal, según zonas, son las más frecuentes. La explicación se halla en las positivas consecuencias que normalmente venía produciendo este tipo de alegación, que por muchas Administraciones municipales era estimada en vía de gestión. 
REVL-1977, núm. . REBES SOLE, JOSE-ENRIQUE. EL CONCEPTO DE EXPLOTACION COMO UNO ...

LA NO SUJECION AL ARBITRIO SOBRE EL INCREMENTO DEL VALOR DE LOS TERRENOS

791

\section{LA SUJECION AL ARBITRIO COMO REGLA GENERAL}

El arbitrio sobre el incremento del valor de los terrenos se halla regulado en los artículos 510 y siguientes de la Ley de Régimen local, texto refundido de 1955; en la Base 27 de la Ley de Bases del Estatuto de Régimen local, y, especialmente, en los artículos 87 a 89 del Real Decreto que la desarrolla.

No ha habido, en este aspecto, modificaciones espectaculares, y sí tan sólo breves adaptaciones. El artículo 510 de la Ley de Régimen local establece que «constituye objeto de este arbitrio el incremento que, en un período determinado de tiempo, experimenta el valor de los terrenos sitos en el término municipal del Ayuntamiento de la imposición, estén o no edificados, con excepción de aquellos afectos a las explotaciones agrícolas, forestales, ganaderas o mineras y que no tengan, además, la consideración legal de solares a tenor de lo dispuesto en el artículo 499».

Del contenido de este precepto se desprende que el ámbito del arbitrio es extraordinariamente amplio. Alcanza, en principio, a todos los terrenos (3), prescindiendo de si han sido o no objeto de

(3) La sujeción al arbitrio como regla general ha sido formulada expresamente en numerosísimas sentencias del Tribunal Supremo, de las que entresacamos las siguientes: $\alpha_{\ldots} .$. el arbitrio puede quedar extendido, en principio, a fincas radicantes en cualquier punto del término municipal..." (29 de marzo de 1966); «... sujetos por la regla general, ya se vio que lo estaban todos los sitos en el término municipal, se hallen o no edificados...n (6 de febrero de 1967); en igual sentido la de 14 de junio de 1968; «... el arbitrio sobre el incremento del valor de los terrenos grava, en principio, a todos los del término municipal, sin más excepción que aquellos que forman parte de una explotación...» (28 de abril de 1969); «... en principio grava a todos los terrenos del término municipal, sin otra excepción que aquellos que careciendo de las condiciones necesarias para merecer la calificación de solares formen parte de una explotación...» (22 de mayo de 1969); o la de 8 de mayo de 1970, que establece: «... es principio general que queden sujetos al arbitrio de plusvalía las transmisiones de todos los terrenos situados en el término municipal del Ayuntamiento exaccionante, con la única excepción...»; «... en principio se hallan "sujetos" a este arbitrio todos los terrenos del término municipal cuya Corporación haya acordado establecer este arbitrio, lo mismo los del casco que los del ensanche o del extrarradio..." (18 de junio de 1970); sigue el mismo criterio la de 5 de marzo de 1971; «... el arbitrio sobre el incremento del valor de los terrenos sujeta, en principio, y como norma general, a todos los terrenos del término municipal, tanto si son solares como si no lo son, estén edificados o no...» ( 2 de julio de 1971); "... grava con independencia de aquella calificación a todos los terrenos sitos dentro del término municipal, excepto aquellos que estén destinados a alguna de las explotaciones..." (18 de mayo de 1972); "... que no es válido alegar que por razón de que no se haya concretado la acción municipal en la zona en que esté sito el terreno transmitido no es de aplicar el arbitrio, pues basta que sea un terreno sito en el término del Municipio" (30 de noviembre de 1973); "... se hallan sujetos todos los terrenos del término municipal, salvo...) (7 de febrero de 1974); «... el principio general en el susodicho arbitrio es de la sujeción a él 
edificación, con la salvedad que el mismo texto contempla en favor de aquellos terrenos que se hallen afectos a una de las explotaciones mencionadas y que, además, no tengan la calificación de solares de acuerdo con la propia Ley de Régimen local. Requisitos que, como puede verse con claridad, han de darse de forma conjunta y simultánea (4).

Por su parte, el artículo 87 del Real Decreto establece que: "Constituye el objeto del impuesto sobre el incremento del valor de los terrenos el que hayan experimentado durante el período de imposición: a) Los terrenos cuya propiedad se transmita por cualquier título, o aquéllos sobre los que se constituya o transmita cualquier derecho real de goce limitativo del dominio. $b$ ) Los terrenos que pertenezcan a personas jurídicas. No estará sujeto al impuesto el incremento que experimente el valor de los terrenos destinados a una explotación agrícola, ganadera, forestal o minera, a no ser que dichos terrenos tengan la condición de solares, o estén calificados como urbanos o urbanizables programados, o vayan adquiriendo esta última condición con arreglo a lo dispuesto en la Ley sobre Régimen del Suelo y Ordenación urbana».

El planteamiento legal es, como vemos, básicamente el mismo. Las variaciones las podemos precisar en la siguiente forma: Primera, una mejora técnico-legislativa en relación al precepto anterior; entre otros aspectos conviene resaltar que ha suprimido la referencia a las «excepciones» y ha introducido el término de no sujeción, que es el que corresponde (5). Segunda, se ha ampliado

de las transmisiones de todos los terrenos..." (28 de mayo de 1974); "... en principio se halla sometida al arbitrio toda transmisión de terrenos, y siendo excepcional la exención... (14 de octubre de 1975), sentencia de 23 de mayo de 1977, etc.

(4) La coincidencia de los dos citados requisitos que dan lugar a la no sujeción debe realizarse en el momento del devengo, que la Ley determina en el momento de la transmisión. El Tribunal Supremo ha insistido reiteradamente sobre esta exigencia. Así pueden verse las siguientes sentencias: 18 de marzo de 1959, 21 de junio de 1963, 14 de mayo y 9 de junio de 1965, 27 de marzo de 1967, 7 de octubre de 1968, 3 de noviembre de 1969, 8 de mayo de 1970, 5 y 19 de noviembre de 1971 y otras.

(5) La jurisprudencia ha utilizado, con alguna frecuencia, los términos «excepción» y "no sujeción» como si fueran sinónimos, e incluso en alguna sentencia se ha introducido, imaginamos que involuntariamente, el de «exención", imprecisión cuyo origen hay que buscarlo en la terminología utilizada inicialmente por los textos legales. Entre las sentencias que utilizan los primeros términos de forma indiferenciada podemos citar, entre otras, las siguientes: 4 de marzo de 1968 ( $\alpha$... los terrenos no tenían nada de explotación agrícola... que en este caso habría sido lo único válidamente invocable para eximirlos.... ), 30 de mayo de 1968,20 de febrero de 1969 y 5 de julio del mismo año; por su parte, se refieren a la «exención" otras como la de 18 de junio de 1970 ( «... en suma, "exentos" solamente los que no siendo solares están afectos a explotaciones agrícolas, forestales... y esto 
formalmente el ámbito del arbitrio al añadir, además de la condición de solar, que los terrenos tengan la calificación de urbanos o urbanizables programados o adquieran esta condición de acuerdo con la Ley del Suelo (6). Con esta modificación se ha producido la lógica congruencia entre dos normativas cuya esfera de actuación es la misma. El tradicional y dispar criterio de «solares» a efectos de la Ley de Régimen local, y por extensión para el arbitrio de plusvalía, y "solares» a efectos de la Ley del Suelo ha quedado superado y resuelto (7).

-para la exención fiscal- con toda la significación de una explotación efectiva...») y la de 28 de febrero de 1973; se siguen refiriendo al concepto "exención" las sentencias de 14 de octubre de 1975, 28 de febrero y 15 de noviembre de 1976.

No obstante, otra orientación jurisprudencial, sin duda con mayor acierto, ha venido utilizando el término adecuado. Así, la sentencia de 27 de diciembre de 1967 ( ... el destino agrícola, forestal... que aquel - precepto- exige para gozar de la no sujeción a dicho gravamen...n); en igual sentido las de 18 de mayo, 5 de julio y 27 de octubre de 1972 y 28 de marzo de 1974, entre otras.

Los pocos autores que se han referido al tema que contemplamos, tampoco han prestado atención a la inadecuada utilización del término previsto en la Ley, salvo algunas excepciones, entre las que citamos a González Pérez, Jesús, "La excepción del arbitrio de plusvalía de los terrenos afectos a explotaciones agrícolas, forestales, ganaderas o mineras", El Consultor de los Ayuntamientos, núm. 14, 1967, pág. 629; D'OoON, Joaquín, «La tributación de las plusvalías patrimoniales en la Hacienda: Problemática teórica y soluciones jurídico-positivas", Revista de Derecho Financiero y Hacienda Pública, vol. XX, núm. 88, julio-agosto 1970, pág. 204, aunque parece hacerlo con cierta prevención, pues dice: «Al analizar el hecho imponible hemos considerado, como más propio técnicamente, las excepciones de las explotaciones agrícolas, forestales, ganaderas y mineras, que al mismo tiempo no tengan la consideración de solar, conceptuarlas en la esfera de las no sujeciones que de las exenciones" (el subrayado es nuestro). Con mayor claridad, RodRfGuEz GARCfA, Enrique B., El arbitrio municipal de plusvalia en la jurisprudencia del Tribunal Supremo, Granada, 1976, pág. 116.

Con anterioridad, y bajo la vigencia del Decreto de Ordenación provisional de las Haciendas locales de 25 de enero de 1946, SILVÁN se refirió brevemente a esta cuestión, algunas veces con el nombre de "exenciones legales" - tal vez por la inercia de la terminología utilizada por el Real Decreto creador del gravamen-; sin embargo, cuando se ve en la necesidad de hacer una sistemática general de los actos sujetos y no sujetos, los encuadra dentro de estos últimos. (Tratado del impuesto municipal de plusvalia, Librería Bosch, Barcelona, 1950, päg. 118.)

Sobre este punto también conviene recordar que ya el Ayuntamiento de Barcelona en sus Ordenanzas fiscales reguladoras del arbitrio que rigieron para el año 1952 se refería al supuesto que contemplamos, en su artículo 29 como un supuesto de no sujeción.

(6) Vid. los artículos 78 y 79 y concordantes del Texto refundido de la Ley sobre Régimen del suelo y Ordenación urbana (Real Decreto 1.346/1976, de 9 de abril).

(7) Con anterioridad, la jurisprudencia se manifestaba, de forma reiterada, en el sentido de la inaplicabilidad del concepto de solar previsto en el artículo 63 de la Ley del Suedo de 1956, a efectos del arbitrio de plusvalía, pues entendía que una cosa era el concepto de solar a efectos urbanísticos y otra distinta a efectos fiscales.

La doctrina no se planteó esta cuestión, a excepción' de alguna salvedad, entre la que citamos como más destacada a FoRNESA RIBO, Ricardo, «Estudio crítico sobre las Haciendas municipales», en la revista Hacienda Pública Española, núm. 4, 1970, página 88. 
Prescindiendo de esta última cuestión, de la que no vamos a ocuparnos, el esquema ofrecido por la anterior Ley de Régimen local y por la nueva regulación del Real Decreto es similar.

En efecto, para que la Administración se halle legitimada, en principio (8), para poder practicar la correspondiente liquidación por el arbitrio sobre el incremento del valor de los terrenos, es suficiente con que éstos se encuentren, como hemos visto (9), dentro del término del Municipio de la imposición y cuya propiedad haya sido objeto de transmisión, o constitución o transmisión de cualquier derecho real de goce, limitativo del dominio, o simplemen el transcurso del período de diez años, cuando la titularidad corresponde a alguna persona jurídica.

\section{LOS SUPUESTOS DE NO SUJECION}

La extraordinaria amplitud de los preceptos que hemos comentado, que consagran la regla general, también tienen su delimitación por la vía de la determinación de los supuestos de no sujeción. Este planteamiento en la práctica ha dado lugar, sigue y seguirá motivando numerosas cuestiones y problemas a los que nos referiremos.

Estos supuestos de no sujeción venían configurados en el artículo 510 de la Ley de Régimen local, texto refundido de 1955, como aquellos casos en los que se daba la circunstancia de la existencia de un terreno afecto a una explotación agrícola, forestal, ganadera o minera y que, además, no reuniese la condición legal de solar según la misma Ley. Hoy, como hemos visto, en el Real Decreto ha sido sustituido el concepto de solar de la Ley de Régimen local por el de la Ley del Suelo, añadiéndose, además, aquellos que estén calificados como urbanos o adquieran esta calificación. Son dos circunstancias que se deben seguir dando de forma acumulativa en el momento de producirse el devengo del arbitrio: la condición positiva, la de la explotación de que se trate, y la negativa, de la inexistencia de la condición de solar o calificación de terreno urbano o urbanizable. Como ya hemos dicho, tan sólo nos referimos al' primero de los aspectos mencionados.

(8) Hacemos esta reserva para salvar las exigencias de tipo formal.

(9) Vid. nota 3. 
REVL-1977, núm. . REBES SOLE, JOSE-ENRIQUE. EL CONCEPTO DE EXPLOTACION COMO UNO ...

LA NO SUJECION AL ARBITRIO SOBRE EL INCREMENTO DEL VALOR DE LOS TERRENOS

\section{TERRENOS AFECTOS A UNA EXPLOTACION AGRICOLA, FORESTAL, GANADERA O MINERA (10)}

\section{Dificultades PaRa la DETERMrNación DEL CONCEPTO DE EXPLOTACIÓN}

La gran dificultad que plantea la correcta apreciación de la existencia de este tipo de explotaciones proviene de la ausencia en nuestro ordenamiento local de lo que legalmente deba entenderse por «explotación» (11). Esto es lo que ha contribuido, por una parte, al gran número de reclamaciones y recursos sobre esta materia invocando pretendidas explotaciones $\mathrm{y}$, por otra parte, numerosísimos pronunciamientos de los Tribunales.

No se nos escapa la complejidad que supone la formulación de un concepto jurídico para la determinación de lo que haya de entenderse por «explotación» a los efectos del arbitrio sobre el incremento del valor de los terrenos; no obstante, creo que sería conveniente, aunque fuera de forma indirecta, intentar una delimitación legal en beneficio de la seguridad jurídica (esto, en definitiva, fue lo que hizo el Estatuto de 1924 por medio del artículo 386, 3.). Con ello se evitarían, además, las dificultades interpretativas con que se encuentra el Tribunal Supremo.

(10) En este epigrafe se recogen parte de las consideraciones vertidas en el siguiente trabajo: REBÉS SOLÉ, José-Enrique, "Evolució jurisprudencial del concepte d'explotació als efectes de l'arbitri sobre l'increment del valor dels terrenys», en Revista Jurídica de Cataluña, núm. 2, abril-junio 1977, en especial págs. 28 y sigs.

(11) Parecida afirmación, aunque referida a todo nuestro Derecho, se encuentra formulada por Luna SERRANO, Agustín, "Limitaciones al derecho de propiedad que se consideran necesarias para el desarrollo de la explotación agrícola y para la ordenación del territorio», en Jornadas italo-españolas de Derecho agrario, Universidades de Salamanca y Valladolid, Valladolid, 1976, pág. 539.

Para Rodrfguez Garcfa (refiriéndose al arbitrio de plusvalía), lo importante no es el concepto de explotación, sino precisar cuándo un terreno to está afecto a ella. Esto -según dicho autor- lo determina el valor del terreno, de forma que si tal valor no viene concretado por la renta rústica, sino por otras causas, quedará sujeto al arbitrio. Por lo que concluye que no quedarán sujetos aquellos terrenos cuyo valor y su incremento que hayan experimentado, vengan determinados por la intensidad con que dicho terreno puede ser utilizado en una actividad de producción agrícola, así como por su calidad y situación en función de dicha actividad (El arbitrio..., págs. 126 y 128). Este planteamiento puede, en principio, parecer atractivo y correcto; sin embargo, la cuestión no se plantea exclusivamente en la forma en que lo hare el mencionado autor, pues la determinación de lo que deba entenderse por aexplotación» sigue teniendo eficacia decisoria, especialmente para aquellos casos en que el valor del terrreno quede justificado por la explotación agraria. 
Estas dificultades han sido también puestas de manifiesto por el propio Tribunal Supremo en alguna ocasión al decir que «el ideal de la completa determinación no se logra de igual forma (se está refiriendo al concepto de solar del artículo 499 de la Ley de Régimen local), como ocurre con los conceptos de explotación agrícola, forestal, ganadera o minera; por tratarse de conceptos sólo determinados indirectamente..., puesto que para dar con ellos ni es suficiente con remitirse a la experiencia vulgar ni tampoco dependen por entero de la experiencia técnica, requiriendo más bien el empleo de juicios de valor» (5 de abril de 1973). En otra sentencia posterior, refiriéndose a la misma cuestión, pone de manifiesto la problemática del concepto de explotación agrícola, añadiendo que "constituye uno de los elementos llamados conceptos indeterminados, cuya delimitación es transferida al Juez por el legislador» (14 de octubre de 1974) (12).

Quizás una de las sentencias más representativas del problema que comentamos, y del reconocimiento por parte del Tribunal Supremo de las dificultades apreciadas, es la de 9 de febrero de 1974, que destaca el perfeccionamiento logrado por el artículo 99, 1, de la Ley Especial de Madrid, que tiene en cuenta el valor de los terrenos como elemento determinante, «lo cual evita - dice- tanto el no gravamen de plusvalías realmente existentes... como el que la jurisprudencia tenga que moverse como lo ha hecho en los casos a que se refieren las sentencias antes citadas..., con el peligro inherente a todo sistema montado casuísticamente y a base de presunciones y datos de no fácil constatación».

En vía jurisdiccional se han hecho esfuerzos para intentar buscar el concepto de explotación (me refiero, ahora, en concreto al de carácter agrícola) en preceptos ajenos a la legislación local, pero todo ello sin gran éxito (13), pues el concepto que de finca

(12) Estas dos sentencias son exponentes de la tardía recepción por el Tribunal Supremo de la teoría de los "conceptos jurídicos indeterminados», que inicialmente fue elaborada por GARCfA DE ENTERRIA en el conocido artículo "La lucha de las inmunidades del Poder en el Derecho administrativo" (en Revista de Administración Pública, núm. 38, 1962). La primera de las sentencias citadas es recogida también por SAINZ MORENo (en Conceptos jurídicos, interpretación y discrecionalidad administrativa, Ed. Civitas, S. A., Madrid, 1976, pág. 290, nota 206), aunque como ejemplo de las que no hacen mención expresa a la naturaleza de concepto jurídico indeterminado, punto en el que no coincidimos, pues nos parece bastante clara; no obstante, mucho más elocuente es la sentencia que referimos en último lugar -que el mencionado autor no recoge-, y en la que la cuestión se plantea en toda su plenitud:

(13) aIncide en error el recurrente al apoyar, además, sus recursos en la cita del artículo 43 de la Ley de Arrendamientos rústicos, 44 del Reglamento Hipote- 
agraria tiene el Derecho privado, aunque se le pueda aproximar bastante (14), no es el de explotación. No obstante, en alguna sentencia del Tribunal Supremo, relativamente reciente, se dice que «ha tomado carta de naturaleza en nuestro Derecho tributario al definir la Ley de Reforma Tributaria de 1964 (15), como explotación agrícola cualquier extensión de terreno, compuesto o no de varias parcelas, siempre que constituyan una unidad orgánica que de forma técnicamente autónoma tenga por objeto una producción agrícola o forestal en la que concurra una actividad del titular y un riesgo asumido por el mismo -artículo $7 .^{\circ}, 2-$ (sentencia de 14 de octubre de 1975). Concepto que se halla muy próximo al de «explotación agraria», por lo que resulta extraño que no hubiese sido invocado mucho antes.

\section{APROXIMACION JURISPRUDENCIAL AL CONCEPTO TRADICIONAL DE EXPLOTACIÓN}

El Tribunal Supremo ha procurado suplir, por medios interpretativos, la ausencia en nuestro ordenamiento de lo que deba entenderse por «explotación». Así, dicho Tribunal empezó haciendo una simple distinción, a efectos de las explotaciones agrícolas, entre los terrenos simplemente rústicos y los meros aprovechamientos, para terminar exigiendo una auténtica explotación.

cario, la Ley de 27 de abril de 1945 y la Ley de Concentración parcelaria, porque, aparte de no contener estas leyes un concepto de explotación agrícola de validez general, basta la sola detenida lectura de los preceptos invocados para llegar a la conclusión de que: a) el artículo 43 de la Ley de Arrendamientos (rústicos) no define la explotación agrícola, sino que cita elementos que, a los efectos de la aparcería, deben entenderse comprendidos en el concepto "capital de explotación" a que se refiere el artículo anterior; $b$ ) el artículo 44 del Reglamento Hipotecario tampoco define la explotación, sino que considera inscribibles, como una sola finca registral, las explotaciones agrícolas que reúnen determinados requisitos; c) la Ley de 27 de abril de 1945 se refiere a un determinado tipo de explotación agrícola, que califica de ejemplar, y d) la Ley de Concentración parcelaria supone la existencia de explotaciones agrícolas constituidas por minúsculas parcelas y pretende combatir esta situación reestructurando la propiedad agrícola hasta hacerla económicamente rentable, lo que ciertamente no se comprende qué relación puede tener con el concreto objeto de este litigio» (sentencia de 19 de noviembre de 1962).

(14) Sobre este punto puede verse Cano Tell, Celestino A., «El concepto de finca agraria, dentro de la clasificación de los bienes inmuebles por naturaleza, en el Derecho españoln, en Anuario de Derecho Civil, tomo XXII, julio-septiembre, 1969, páginas 529 a 543 .

(15) Ballarfo Marcial, Alberto, destaca como verdadero acontecimiento la referencia de la explotación agrícola en dicha Ley (Derecho agrario, Editorial Revista de Derecho Privado, Madrid, 1965, pág. 271). 
La explotación inicialmente la definió como "la aplicación de la actividad humana con fines de aprovechamiento y de utilidad» (sentencia de 19 de octubre de 1967), marginando aquellos casos en "que el cultivo fuese transitorio con miras a su terminación y en pequeña escala...» (sentencia de 18 de junio de 1968); añadiendo en otra que, "gramaticalmente, explotación significa acción y efecto de explotar, y en sus acepciones corrientes, utilidad de un negocio, conjunto de elementos dedicados a una granjería...» (sentencia de 8 de abril de 1968); procurando acercarse a la verdadera explotación, que es la que "... lleva implícita la idea de algo sistemático, exclusivo, permanente (existente con anterioridad al momento de la transmisión y en el momento mismo)..., una tal dedicación del terreno, un tal destino (previo habitual y con sustantividad propia y finalidad útil...") (sentencias de 19 de noviembre de 1969 y 18 de junio de 1972); la explotación exige algo más que un simple aprovechamiento, pues «no es válido legal ni económicamente confundir la naturaleza o destino agrícola de una finca con la existencia real y efectiva de una explotación que exige la demostración de un capital y trabajo puesto por la empresa en actividad para la explotación de la finca o terrenos" (sentencia de 5 de noviembre de 1973); c aquella otra en la que también está latente la idea de empresa «... es preciso que se acredite que el terreno en cuestión aparece integrado en una empresa o actividad organizada que, con todos los elementos objetivos y subjetivos que la misma dispone, realice el aprovechamiento agrícola del mismo...» (sentencia de 17 de mayo de 1974); con toda esta orientación se ha procurado siempre marginar del concepto de explotación todas aquellas actividades que pudieran ser «improvisadas para mantener las apariencias de explotación...» (sentencia de 4 de marzo de 1969), que en muchas ocasiones «se cubre sobre la marcha o a posteriori...» (sentencia de 5 de julio de 1969), eliminando también aquellas que se llevasen a cabo "de una manera esporádica y sin sustantividad propia» (sentencia de 18 de mayo de 1972).

Este criterio interpretativo del Tribunal Supremo ha sido, ciertamente, al propio tiempo correcto y riguroso, pues por medio de su aplicación se ha hecho incidir dentro del ámbito material de sujeción al arbitrio supuestos que de otra manera habrían eludido el gravamen municipal. No obstante, como hemos de ver, esta orientación habría de resultar insuficiente. 
REVL-1977, núm. . REBES SOLE, JOSE-ENRIQUE. EL CONCEPTO DE EXPLOTACION COMO UNO ...

LA NO SUJECION AL ARBITRIO SOBRE EL INCREMENTO DEL VALOR DE LOS TERRENOS

3. Delimitación actual por el Tribunal Supremo del concepto DE EXPLOTACIÓN

El hecho del gran número de reclamaciones y recursos basados en la existencia de distintos tipos de "explotaciones", por una parte $\mathrm{y}$, por otra, el notable aumento del valor de determinados terrenos, fruto fundamentalmente del desarrollo turístico en nuestro país, y en particular de la proximidad de determinados terrenos a zonas de aquel interés, hizo que amplias zonas alcanzasen unas valoraciones que nunca se hubiese podido imaginar y una expectativas todavía mayores. Esta situación podría resumirse diciendo que la mejor actividad a la que podían destinarse estos terrenos era simplemente la de aguardar o esperar. Situación simple, pero muchas veces significativa.

Consciente de este problema nuestro Alto Tribunal, que no sólo no había prestado con anterioridad atención a esta cuestión, sino que expresamente la había rechazado (16), empieza a partir de 1968 a establecer un nuevo criterio de apreciación, que es el que examinamos a continuación.

Que nosotros sepamos, la atención al "rendimiento» empezó a tomar cuerpo en una sentencia del Tribunal Supremo de 8 de abril de 1968, que ratificó una resolución del Tribunal Económico-Administrativo Provincial de Barcelona. En dicha sentencia, después de hacer un análisis gramatical de lo que entiende por explotación, añade que «... ya resulta extraño que ocho o nueve propietarios tengan una comunidad dedicada a una explotación de unos setenta pinos cada uno que tras muchos años de gastos llegaría uno de escaso rendimiento en el mejor supuesto; también contradice el crite-

(16) El tema de la deficiente rentabilidad de las fincas, aunque como decimos no fue atendido, había sido puesto de manifiesto por alguna Administración municipal bastante tiempo antes. Así, en la sentencia de 19 de noviembre de 1962 se dijo: «Incide en error el recurrente al apoyar, además, sus recursos en la cita del artículo..., y pretende combatir esta situación reestructurando la propiedad agricola hasta hacerla económicamente rentable, lo que ciertamente no se comprende qué relación puede tener con el concreto objeto de este litigio" (con mayor extensión puede verse esta sentencia en la nota 13). En la de 21 de junio de 1963 se estableció: "...es infundada la tesis de la representación municipal de que únicamente quedan excluidas las fincas económicamente rentables...". Cierto que en este caso la argumentación se efectuó sobre la base del concepto de rentabilidad legal y no real, pues en la misma se añadió: "... según los criterios que revela una legislación promulgada bajo la preocupación de mantener unidades de cultivo adecuadas, cualquiera que sean las consecuencias que en el orden civil puedan producirse.... 
rio de la Sala el precio satisfecho por una finca improductiva, que fue de 250.000 pesetas confesadas, más gastos e impuestos, que podía fácilmente sobrepasar las 400.000 pesetas, que no tiene explicación más racional que la que el vendedor vendía un terreno revalorizado con próxima locación urbanística en zona de reserva y en lugar de turismo, sin su acción ni intervención por su parte, y a cuya valoración, por el contrario, contribuyó eficazmente la labor y acción municipal...»; le siguió a esta sentencia otra que sentó una doctrina mucho más clara al decir que «... no puede calificarse de explotación agrícola aquella cuyos rendimientos son prácticamente simbólicos en relación a su valor real, que en este caso puede estimarse como extraordinario, con un incremento de valor que sobrepasa... y con la natural presunción... de que la dedicación a la agricultura es prácticamente irrelevante» (28 de abril de 1969); en otras se ha hecho especial énfasis en la valoración del terreno «... que viene a resultar patentemente excesivo para un terreno agrícola y no inadecuado, sino muy apropiado a un terreno urbano" (4 de marzo de 1969).

Con estas sentencias se inició un criterio que ya no habría de abandonarse, sino en alguna rarísima excepción, por lo que constituye hoy un criterio fundado en reiteradísima jurisprudencia de nuestro Tribunal Supremo (17).

(17) A las sentencias que hemos citado siguieron otras muchas, entre las que citamos las siguientes: la de 22 de mayo de 1969, que estableció que "... aunque tenga plantada de caña de azúcar en una tercera parte no debe ser reputada como explotación agrícola, según se pretende, pues estando estos terrenos situados en una zona privilegiada de interés turístico, motivo único que permite alcanzar tan elevadas cotizaciones, la explotación de esos terrenos resultaría ruinosan; la de 4 de noviembre de 1969: «... la existencia de unos árboles cuyos rendimientos han de reputarse irrelevantes, y hasta puramente simbólicos, en relación del valor del terreno que exclusivamente ha podido alcanzar un incremento extraordinario que evidencia lo intrascendente de la supuesta explotación...n; la de 31 de octubre de 1970: «... ni la mera aportación de recibos, en número de seis, procedentes de distintos organismos y acreditativos de diversos pagos, supone otra cosa que otorgar el carácter de simple finca rústica al terreno transmitido; la hipotética existencia de unos árboles cuya proporción valorativa, en relación con la totalidad de la finca, no se determina no puede suponer la existencia de una explotación agrícola...n; la de 11 de marzo de 1971: a... pues los rendimientos en relación con la extensión de la finca han de reputarse irrelevantes, y hasta puramente simbólicos, en relación con el terreno, que dada su situación... ha podido alcanzar un incremento extraordinario, y ello evidencia lo intrascendente de la supuesta explotación no probadan; la de 19 de noviembre de 1971: a... la existencia de un mero y preterido cultivo sin proporción valorativa en relación a la totalidad de la finca de que se trata, no puede suponer la existencia de una explotación agrícola, para lo cual es necesario una apreciación conjunta de la prueba aportada, conforme a las reglas de la sana crítica, con la natural presunción iuris tantum de que la dedicación a la agricultura en cualquier forma de cultivo no ha de ser simbólica e irrelevante, respecto a la valoración esencial de-la finca, y aun referida al mo- 
REVL-1977, núm. . REBES SOLE, JOSE-ENRIQUE. EL CONCEPTO DE EXPLOTACION COMO UNO ...

Como hemos tenido ocasión de ver, son dos los extremos que fundamentalmente se tienen en cuenta en las referidas sentencias. Uno, la insuficiencia de los rendimientos que se obtienen mediante el aprovechamiento agrícola o pretendida explotación agrícola, y otro, igualmente importante, cual es el valor real del terreno de que se trata. Extremos que, puestos en combinación, ponen de manifiesto la desproporción entre los dos. Con ello, el Tribunal Supremo ha pretendido, creemos, desplazar aquellos casos no sólo de explotaciones dudosas, o cuando menos indebidamente acreditadas, sino primordialmente someter al arbitrio aquellos incrementos de valor ajenos a la actividad propia de la explotación.

mento de la transmisión, sino acreditativa de una producción de resultados sensiblesn; en igual sentido la de 14 de febrero de 1972; de particular interés e incluso con un criterio más exigente en orden a la apreciación de la prueba citamos la de 27 de octubre de 1972: «... al no expresarse los saldos y el movimiento de esa cuenta corriente nos impide saber si existió o no desde 1958 una explotación agrícola, una empresa, es decir, un capital en movimiento para la producción agrícola o si quedó reducida a los ingresos y gastos de una casa y jardines como residencia de gran lujo...»; en idéntico sentido las de 1 de diciembre de 1972 y 14 de febrero de 1973; la de 2 de marzo de 1973 insiste en el criterio de la proporcionalidad: «... no existe una auténtica explotación si no se acredita que los rendimientos de la misma guardan la debida proporción con la extensión y con el valor y capacidad productiva de la finca..."; en la misma línea las sentencias de 21 de marzo y 5 de abril de 1973; la de 22 de enero de 1974: «... no existe auténtica explotación si no se acredita que los rendimientos de la finca gravada guardan la debida proporción con su valor en venta...»; también la de 18 de junio de $1974 ;$ «... la explotación... no sólo se demuestra con datos catastrales o extracatastrales indicadores que una determinada finca revela una "utilización"..., incluso aunque se diga que tal "dedicación" es la existente en el momento de la transmisión..., sino que es menester además, entre otros aspectos del problema, que se ponga claramente de relieve cuáles son específicamente los "rendimientos de la finca" y "en qué proporción" éstos se encuentran con el valor de aquélla.... (7 de febrero de 1974); "... la explotación ha de ser relevante o sustancial integrante de una unidad orgánica que tenga por objeto la producción agrícola, constando la realidad de los elementos subjetivos -actividad del titular y riesgo cuantitativo asumido por el mismo-, objetivos -cultivos concretos en cuanto a clase y naturaleza, y no de pequeña escala, transitorios, improvisados, irrelevantes o simbólicos-y económicos -rendimientos que han de guardar la debida proporción con la extensión, capacidad productiva o valor de la finca que han de ser suficientes y productivos-..., precisando así la noción y la problemática de explotación agrícola, constitutiva de uno de los llamados "conceptos indeterminados", categoría cuya delimitación es transferida al Juez por el legislador" (14 de octubre de 1974); "... no es suficiente la existencia de cultivos irrelevantes en relación con el valor de la finca...” (27 de septiembre de 1974); «... el concepto de explotación agrícola no coincide con el de finca rústica...; la exención nace de la real explotación, concepto jurídico elaborado en principio por el Derecho privado, que contempla una realidad social preexistente con especial significado económico...» (14 de octubre de 1975); «... por lo que resulta indispensable que se ponga claramente de relieve... cuáles son específicamente los rendimientos de la finca, qué cuantía alcanzan dichos rendimientos y qué proporción guardan éstos con el valor de aquéllos..." (28 de febrero de 1976); "... no puede considerarse exento un terreno que se dice dedicado a... si los rendimientos no guardan proporción :con una explotación de esta clase..." (2 de febrero de 1976); «... a los efectos de la no sujeción al arbitrio, no basta con la simple afección de 
Con la introducción de estos nuevos elementos, conjugados debidamente con los que ya de forma tradicional había establecido para determinar lo que debía entenderse por explotación, el Tribunal Supremo nos ofrece un concepto más depurado, más realista y ciertamente más amplio. Pues define la explotación como la «dedicación permanente del terreno, utilizando elementos materiales y personales e incluso técnicos para la obtención de rendimientos económicos, verdadera empresa...» (9 de julio de 1973), «... que han de guardar la debida proporción con la extensión, capacidad productiva o valor de la finca, que han de ser suficientes...» (14 de octubre de 1974) (18).

En algunas otras sentencias posteriores el propio Tribunal acude (parece, en busca de una mayor cobertura jurídica a su interpretación) al artículo $7 .^{\circ}, 2$, de la Ley de Reforma del Sistema tributario de 1964 (19), al considerar que en este precepto se encontraba una definición del concepto de explotación. Debe precisarse que este texto se refiere a la contribución territorial rústica y pecuaria, por lo que luego se recogió en forma prácticamente exacta en el artículo 34 de este texto. En esta misma línea, y tendente a reforzar los conceptos manejados, de distinción entre las «explotaciones» y las

un terreno a un determinado cultivo o plantación, sino que es menester, además, que sus rendimientos guarden la debida proporción con la extensión de la finca y con el valor, sobre todo, que a la misma deba reconocerse, pues la explotación agrícola no significa lo mismo que finca rústica o cultivada, sino unidad de producción agraria en que se combinan diversos factores; sólo uno de los cuales está constituido por la tierra, pero al que hay que agregar otros, no menos importantes, como el de la utilización de técnicas adecuadas y la tendencia a la producción de bienes proyectados al mercado, inclusive con el elemento complementario de determinado riesgo..." (sentencia de 15 de octubre de 1976); "... una cosa es el carácter de finca rústica y otra muy distinta la calificación como verdadera de "explotación agrícola", de la misma manera que el artículo 24 de la Ley General Tributaria de 28 de diciembre de 1963 distingue en su artículo 72 entre "explotaciones" y "meras actividades económicas"..., la explotación agrícola ha dejado de ser un hecho, susceptible de prueba, para pasar a ser un concepto, y cuando la escala de valores llega a establecer diferencias sorprendentes, se produce una corriente que, con independencia de la voluntad del propietario, llega a cambiar la pretérita vocación rústica de los terrenos ante la incontenible realidad urbanística..., son numerosas las declaraciones de la jurisprudencia en el sentido de que no procede la exención del arbitrio si los rendimientos efectivos de la explotación... no guardan una razonable proporción con el valor de la venta de la finca...» (15 de noviembre de 1976); sentencia de 31 de marzo de 1977, etc.

(18) A la vista de esta orientación, RODRfGUEz MORo apunta que tal vez debiera volverse al concepto del Estatuto municipal o al establecido en la Ley Especial de Madrid ( Los terrenos afectos a explotaciones agrícolas en el arbitrio de plusvalía», en REVISTA DE ESTUdiOS DE LA VIDA LOCAL, núm. 181, enero-marzo de 1974, páginas 107 y 108).

(19) Vid. supra, pág. 797. No obstante, no hemos encontrado en las sentencias del Tribunal Supremo ninguna referencia a la Ley de Reforma y Desarollo Agrario, vid. notas 45 a 48 . 
«meras actividades económicas» se intenta hacer un paralelismo con algún otro precepto de la Ley General Tributaria (20). Lo que en todo caso es evidente es que no existe en nuestra legislación un precepto que defina lo que sea una «explotación», ni tampoco la remisión de esta normativa a otra. No obstante, como ya hemos visto, el concepto de «explotación» que se ofrece a los efectos de la contribución territorial rústica es bastante próximo a lo que debe de entenderse por tal concepto.

\section{EXAMEN CRÍTICO DE LA INTERPRETACIÓN FORMULADA POR EL TRIBUNAL SUPREMO}

Como hemos tenido ocasión de ver, nuestro Alto Tribunal sigue un criterio muy restrictivo - según las referencias jurisprudenciales- en orden a la apreciación de la existencia de "explotaciones». Para llegar a este, casi general, criterio utiliza fundamentalmente dos medios que, en el fondo, son coincidentes con la misma orientación. Así, unas veces se limita a ponderar los rendimientos de la «deseada explotación» con una clara tendencia objetivizadora, mientras que en otras presta su atención preferencial al extraordinario valor adquirido por las parcelas, soporte de «invocadas explotaciones", y finalmente utiliza con frecuencia la conjunción de ambos elementos. Con todo ello, las referencias a los escasos rendimientos, a los rendimientos simbólicos, etc., o al extraordinario valor adquirido por el terreno, o a la falta de la debida proporción de los rendimientos con el valor en venta del terreno, etc., son muy frecuentes.

No hace falta hacer grandes análisis para darse cuenta que los conceptos y términos utilizados por el Tribunal Supremo, tales como "valor», "valoraciones», "rendimientos», "proporción», etc., tienen una carga de apreciación económica notoria. La cuestión radica precisamente aquí. ¿La interpretación que efectúa el Tribunal sobre esta materia tiene carácter económico? La contestación parece afirmativa, y la pregunta inmediata. ¿Es esto posible?, ¿cabe esta interpretación?

El artículo 23 de la Ley General Tributaria establece: «1: Las normas tributarias se interpretarán con arreglo a los criterios ad-

(20) 'Así se cita el artículo 72 de dicha Ley, vid. en sentencia de 15 de noviembre de 1976, citada en nota 17. 
mitidos en Derecho», y en su número 2 que «en tanto no se definan por el Ordenamiento Tributario los términos empleados en sus normas, se entenderán conformes a su sentido jurídico, técnico o usual, según proceda». Vamos a referirnos, en primer lugar, al examen del apartado número uno. Su contenido es claro, y de acuerdo con el mismo habrá que recurrir a los criterios interpretativos admitidos en Derecho, es decir, el histórico, el lógico, el gramatical y el sistemático. El planteamiento de la referida norma es correcto, toda vez que resulta congruente que las leyes tributarias no deban ser objeto de un tratamiento hermenéutico diferente del aplicable a las demás normas, pues tan jurídicas son unas como otras. Esta es la justificación última del porqué en materia tributaria se puedan utilizar los criterios admitidos en Derecho. Coherente con esta postura, un sector de la doctrina rechaza la utilización de criterios interpretativos de carácter extrajurídico, y en particular los económicos (21), criterio que había sido expresamente excluido del artículo 23 del proyecto, que parecía permitir prestar más atención a la finalidad económica (22).

(21) Vid. PeRulles, Juan José, «La interpretación y el Derecho tributario», en Problemática de la ciencia del Derecho, Estudios en homenaje al profesor José María Pi y Suñer, Facultad de Derecho de la Universidad de Barcelona, Bosch Casa Editorial, Barcelona, 1962. FERNÁNDEZ ORDOÑEZ, Francisco José, "La interpretación de las normas tributarias», en XXI Seminario de Estudios de Derecho Financiero, Editorial de Derecho Financiero, Madrid, 1966, págs. 201 a 208. CorTÉs, Matías, Ordenamiento tributario español, Ed. Tecnos, Madrid, 1970, en particular pág. 124 y bibliografía que cita.

(22) $\alpha$ Ya hemos visto que el proyecto habfa incluido entre los criterios de interpretación el económico; la Ley General Tributaria, con indudable acierto, ha omitido aquel criterio y ha señalado los criterios jurídicos como los únicos capaces de conducir la investigación del alcance de las normas tributarias a buen puerto» (CorTés, Ordenamiento..., citado, pág. 124).

En parecido sentido, aunque de forma más matizada, otro autor, César AlBIÑANA, dice: «En este punto... aplaudo la supresión del copiado inciso ( $\ldots$...y teniendo en cuenta su finalidad económica...») en cuanto establece un criterio interpretativo de norma jurídica, pero que juzgo ortodoxo si se invoca para "calificar" el supuesto de hecho que desencadena o no la exacción tributaria» ( El Derecho privado en el ordenamiento tributario españoln, en la obra de Llamas Labella, Miguel Alfonso, Ensayos sobre jurisprudencia tributaria, Estudios de Hacienda Pública, Instituto de Estudios Fiscales, Ministerio de Hacienda, Madrid, 1973, pág. XXXIV).

Para otros autores la supresión no tuvo justificación; vid. ForNesa RIBo, aLa interpretación y aplicación de las normas tributarias», en $X X I$ Conferencia Técnica del Centro Iberoamericano de Administradores Tributarios (Organización y funciones del Departamento de la Administración tributaria), Fábrica Nacional de Moneda y Timbre, Madrid, 1976, pág. 313 y bibliografía que cita.

En el informe de la ponencia se dijo: $\alpha . .$. no parece conveniente que el intérprete pueda utilizar indistintamente, a su arbitrio, criterios económicos y de justicia; por otro lado es evidente que el sentido jurídico de los términos debe prevalecer en la interpretación de la ley sin perjuicio de que, con carácter subsidiario, deban tenerse en cuenta los aspectos técnicos y usuales. Al establecer la permanencia del critero jurídico no se abandona, por otra parte, la consideración económica, toda 
De aceptar este planteamiento como válido habría que llegar a la conclusión de que el Tribunal Supremo está llevando a cabo una interpretación que no es la permitida por la Ley General Tributaria, e incluso se podría sostener que mediante tal hermenéutica se realiza una ampliación del ámbito de aplicación del arbitrio por extensión de uno de los elementos que configura el tributo, que como tal constituye materia reservada a la Ley, según se desprende del artículo 10 de la Ley General Tributaria (23).

Siguiendo esta misma orientación se podrá argumentar que el artículo 23 de la Ley General Tributaria establece que «los términos empleados en sus normas se entenderán conforme a su sentido jurídico, técnico o usual, según proceda», y que quizá por esta vía se podría admitir la interpretación que lleva a cabo el Tribunal Supremo. Pero, como vemos, el contenido de esta norma es puramente declarativo, y, por tanto, tiene ciertamente escasa importancia, por cuanto que lo que debería precisar es cuándo debe proceder un criterio u otro, cosa que, en efecto, no hace, dando lugar a una dura crítica por parte de la doctrina (24). No obstante, prescindiendo de esta cuestión, que si bien es ciertamente importante, no cambia el planteamiento, pues no permitiría otra solución que la utilización de un criterio técnico para determinar lo que deba entenderse por "explotación", lo cual ya se llevaba a cabo para distinguir entre un mero aprovechamiento y una explotación propia-

vez que el Derecho regula las actividades económicas a través de moldes jurídicos, y la recta interpretación de estos últimos conduce a un adecuado análisis de la realidad subyacente".

(23) En relación con la interpretación a la que nos estamos refiriendo; ForNeSA RiBo dice que el Tribunal Supremo ha introducido, entre otros (criterios), «a efectos de determinar la existencia efectiva de explotación agrícola, el relativo a la lógica rentabilidad de los mismos en atención a su precio de venta, criterio que no obstante supone una aplicación extensiva del hecho imponible" (Estudio critico..., op. cit., pág. 68). No obstante, como veremos, este mismo autor, en un trabajo posterior (La interpretación..., op. cit., pág. 335), sostiene una atractiva tesis en orden a la interpretación y aplicación de las normas tributarias.

El tema apuntado en el texto fue tratado con una orientación muy restrictiva en el "XXXVIII Seminario de Investigación», convocado por el Instituto de Estudios de Administración Local, cuyas conclusiones fueron recogidas por ARRoYo, Juan; Masta, Ginés, y ReBés SolÉ, José-Enrique, La práctica de la plusvalia, Instituto de Estudios de Administración Local, Madrid, 1975, págs. 39 y 40. Se trata de una obra de contenido muy vario.

(24) Sobre este punto puede verse: CoRTÉs, Ordenamiento..., op. cit., págs. 112 y sigs., y, más particularmente, RETORTILlO BAQUER, Lorenzo, "La interpretación de las normas según la Ley General Tributaria», en Revista de Derecho Financiero y Hacienda Pública, núm. 54, 1964, pág. 359. LASARTE, Javier, "Significado usual "versus" significado técnico. Un ejemplo de interpretación», en Crónica Tributaria, número 9,1974 , págs. 65 y 66 . 
mente dicha (25). Pero desde este punto de vista no podría tener cabida el criterio del rendimiento proporcional.

Se podrá también recordar que el artículo 25.1 de la invocada Ley General Tributaria establece que «el impuesto se exigirá con arreglo a la verdadera naturaleza jurídica o económica del hecho imponible», y que, por consiguiente, permite una interpretación económica. No creo que éste sea el sentido del precepto que hemos transcrito, aun cuando algún autor le quiera dar unas consecuencias parecidas (26), pues parece claro que no constituye una norma de hermenéutica, a pesar de su errónea sistemática en la Ley; pero lo que en todo caso es evidente es que por medio del artículo 25.1 no se puede producir una ampliación de los hechos imponibles, pues éstos deben seguir teniendo sus respectivos límites (27). Con lo cual hemos de reconducir el problema al punto de partida, pues no aporta nada nuevo.

Frente a la postura que acabamos de exponer -que bien pudiéramos calificar de tradicional-, que rechaza expresamente la interpretación económica, otro sector de la doctrina mucho más reciente, supera no sólo el clásico planteamiento de que las normas tributarias constituyen una materia "odiosa», y que, por tanto, deben ser objeto de una interpretación restrictiva, sino que, adoptando una clara postura progresiva, aceptan no sólo la interpretación económica, sino cualquier otra que permita una justa aplicación

(25) En este sentido, no es de extrañar, sino todo lo contrario, que el Tribunal Supremo haya dado poca importancia a aquellos medios de prueba constituidos por actas notariales en las que el fedatario público, después de dar fe de lo que veía, incluso determinando el número de árboles y tipo de plantación, afirmaba la existencia de una "explotación agrícola», a lo que dicho Tribunal ha declarado y de forma reiterada que el Notario es un técnico en Derecho, pero no en agricultura, para poder precisar si lo que contemplaba era o no una verdadera explotación.

(26) Amorós, N., Ley General Tributaria (arts. 1 al 89), Editorial de Derecho Financiero, Madrid, 1967, dice sobre este punto: "Por ello, si en el fondo no se puede hablar: según la Ley General Tributaria, de una consideración económica total $\mathrm{y}$, en todo caso, de las normas tributarias, puede que por ese otro camino llegásemos a conclusiones parecidas o a la admisión de estos criterios económicos» (páginas 291-292).

Parece seguir un criterio parecido - aunque referido al fraude fiscal- FaIÑa Medin, José A., "Interpretación económica de las leyes tributarias y el fraude fiscal», en Revista de Derecho Financiero y Hacienda Pública, núm. 15, 1975, especialmente página 184 y bibliografía que cita.

(27) El contenido del precepto al que nos referimos ha sido ampliamente criticado por parte de la doctrina más significativa. Véase: CoRTÉs, M., Ordenamien. to..., op. cit., y en particular las referencias que el mismo contiene a MarrfN Retortillo, L., y a SAINZ DE BUJANDA (Ordenamiento..., op. cit., págs. 133 y 135); AlBiÑaNA, César: «El Derecho privado en el ordenamiento tributario español» en Liamas Labella, A., Ensayos..., op. cit., págs. XXXIII y XXXV. 
del Derecho, criterio que parece razonable y que compartimos siempre que no se rebasen los límites de la propia legalidad. El criterio expuesto ha sido sostenido por FoRNESA RIBÓ en un sugerente trabajo (28), en el que argumenta la aceptación de la interpretación teleológica, la económica e incluso la integrativa por vía analógica, como en el caso concreto que nosotros venimos examinando, y en relación al cual dice que «el requisito de la rentabilidad proporcional no está en la norma, pero que, sin duda alguna, está en la finalidad de la misma, que evidentemente completa el marco lógico, obligado y justo del arbitrio... y que, por tanto, se ha obtenido integrando la norma que define el hecho imponible, rellenando por analogía una laguna...» (29).

La problemática más importante que puede plantear esta orientación es la de examinar si produce colisiones con los principios de legalidad que informan el hecho imponible. Por nuestra parte no creemos que tal cosa suceda, pues la incidencia de los incrementos de valor de terrenos cuya causa no se halle en la actividad explotadora, en el ámbito material de sujeción al arbitrio se halla de acuerdo con el fundamento del arbitrio mismo, sin que en este proceso detectemos ninguna vulneración de los elementos esenciales que constituyen el hecho imponible (30).

No obstante todo lo expuesto, parece que una interpretación histórica nos llevaría a unas conclusiones distintas, pero que no habrán de hacer cambiar el criterio mantenido. La actuación del legislador en esta materia no deja de ser contradictoria. Es sabido que el Decreto creador del arbitrio no contempló el valor del terreno como delimitador de su ámbito, pero en cambio sí se introdujo en el artículo 386, 3..$^{\circ}$, al que remitía el 422 del Estatuto de 1924, cuyo primer precepto llevó a cabo una ampliación formal del concepto de solar, pues según este precepto eran solares todos aquellos "cuyo valor corriente en venta excediese del duplo del que resultase de capitalizar la renta que fueren susceptibles de producir, supuesto su aprovechamiento agrícola, y en las condiciones previstas para la evaluación de la riqueza rústica». En este sentido la modificación

(28) La interpretación y aplicación de las normas..., op. cit., págs. 311 a 345.

(29) FORNESA, La interpretación..., op. cit., pág. 335.

(30) Con lo cual rectificamos nuestra postura -que públicamente habíamos mantenido- discrepante de la doctrina jurisprudencial, como, por ejemplo, hicimos con motivo de la celebración de unos Seminarios de Estudios Superiores sobre el régimen tributario español, organizados por la "Sección de Cataluña de la Asociación Española de Derecho Financiero», Barcelona, febrero-marzo 1974. 
introducida por el Estatuto fue un indudable acierto. Pero esta modificación sólo se mantuvo hasta la aprobación de la Ley de Bases de 1945 y publicación del Decreto de Ordenación provisional de las Haciendas locales en 1946, en que se volvió al régimen anterior. La voluntad del legislador fue, pues, bien clara. Aquella regulación se ha mantenido hasta la actualidad, salvo alguna pequeña variante introducida por el artículo 87.2 del Decreto 3.250 , de 30 de diciembre de 1976, al que luego aludiremos.

Parecida orientación a la que se contenía en el Estatuto municipal de 1924 fue la que se introdujo en la Ley de Régimen especial para el Municipio de Madrid, en cuyo artículo 99.1 se sigue un criterio proporcional de valoración (31). Lo cual no deja de ser también un elemento más en contra de la postura del legislador al redactar la normativa para los Municipios sometidos al Régimen común.

¿Cómo debe interpretarse que el artículo 87.2 del Decreto de 30 de diciembre de 1976 (32) no haya introducido en este aspecto ninguna modificación sustancial? No creemos que pueda interpretarse en el sentido de que el legislador no desee la interpretación que lleva a cabo el Tribunal Supremo, o que el precepto le parezca suficiente, pues en este caso su actuación no sería congruente con sus manifestaciones anteriores. Más bien cabe pensar que tal vez no se ha prestado la suficiente atención a esta cuestión, con lo cual, de ser cierta esta opinión, se pondría una vez más de manifiesto la falta de atención con que el tema de las Haciendas locales ha sido abordado por la Administración central.

\section{REFERENCIAS A LA ELABORACION DOCTRINAL DEL CONCEPTO DE EXPLOTACION (AGRICOLA)}

No se pretende aquí hacer un análisis exhaustivo de lo que la doctrina ha entendido por explotación. Nos referiremos tan sólo a

(31) Este precepto establece que aconstituye el objeto de este arbitrio el incremento que en un período determinado de tiempo experimenta el valor de los terrenos sitos en el término municipal, estén o no edificados, con excepción de aquellos situados fuera del casco urbano y afectos a explotaciones agrícolas, forestales, ganaderas o mineras, siempre y cuando que además no exceda su valor corriente en venta en cuatro veces del que resulte de capitalizar la riqueza imponible de contribución rústica que tuvieren fijada o hubiere de fijarse supuesto su aprovechamiento agricolan.

(32) Cuyo contenido vimos en la página 792. 
un nivel aproximativo y principalmente de carácter agrario (33). La finalidad no es otra que la de resaltar las deficiencias legales que la doctrina ha detectado y así suministrar los elementos que se consideran integrantes del concepto de explotación, cuya incorporación en nuestro ordenamiento habría de reportar indudables beneficios en orden a la clarificación del tema.

En el Código civil se encuentran referencias al término «explotación» (34), aunque no al concepto de "explotación». Sobre este punto, LOPEZ JACOISTE hizo un interesantísimo trabajo (35), del que se desprende, para los efectos que apuntamos, las dificultades que encontró, pues para poder delimitar el concepto de explotación tuvo que recurrir a otros conceptos, para de esta forma encontrar su auténtico sentido. Así, y con esta finalidad, analiza la noción de explotación a base de confrontarla con la del «uso», la del "fruto", etc. La idea de explotación la relaciona de forma íntima con la de beneficio y rendimientos, que es la que en definitiva la diferencia del "uso", ya que éste - dice-concluye en el hombre, pues, como se ve, es un aprovechamiento inmediato y directo. La explotación, en cambio, termina en los beneficios (36); y más adelante destaca de la explotación el hecho de que se trata de una actividad (37), para terminar resaltando, dentro del concepto de explotación, las ideas de rendimiento, capital, trabajo, técnica y riesgos.

Estos criterios, por otra parte, ya habían sido apuntados por alguno con evidente claridad, como, por ejemplo, por EzA, que se refirió a la explotación agrícola diciendo que «es toda aquella actividad que tiene por objeto la producción de materias que necesitan

(33) Son varios los autores que prefieren utilizar el término agrario en lugar del agrícola, por entender que aquél es de mayor amplitud y engloba tanto el concepto estrictamente agrícola cuanto el forestal y pecuario.

(34) El artículo 1.056 prevé que el padre que quiera conservar indivisa una explotación agrícola, industrial o fabril, podrá dispone que se satisfaga en metálico su legítima a los demás hijos. Esta misma idea de unidad se encuentra en el artículo 334, núm. 5, del mismo texto, y también en la Ley Hipotecaria.

Mucho más interesante resulta la referencia a «explotación» que contiene el artículo 282 de la Compilación de Derecho civil especial de Cataluña, que aun refiriéndose al usufructo de bosques maderables tiene indudable alcance. Sobre este punto puede verse: ReBÉs SolÉ, José-Enrique, "Notas al título del "usufructo" de la Compilación civil especial de Cataluñan, en Revista Jurídica de Derecho de Cataluña, núm. II, abril-junio 1966, en particular pág. 366.

(35) "La idea de la explotación en el Derecho civil actual», en Revista de Derecho Privado, mayo 1960, págs. 351-371.

(36) LOPEZ JACOISTE, «La idea...», op. cit., pág. 353.

(37) En este mismo sentido, Luna Serrano, Agustín, "Para una construcción de los conceptos básicos del Derecho agrarion, en La problemática laboral de la agricultura, Colegio Universitario San Pablo (C. E. U.), Madrid, 1974, pág. 111. 
de la tierra para su crecimiento y desarrollo con propósito de obtener de ellas un beneficio o una remuneración a los capitales o al trabajo invertidos...» (38).

BALLARí MARCIaL ve en la explotación agraria una unidad técnico-económica formada por la tierra (una o más parcelas, colindantes o no) y demás elementos organizados por el empresario para llevar a cabo una actividad de cultivo, ganadera o forestal (39).

LUNA SERRANo, por su parte, hace especial énfasis en el aspecto económico y dice de la explotación que "ha de considerarse siempre como una actividad racionalmente organizada y cuyo desenvolvimiento tiene lugar mediante el sometimiento relativo de la vida vegetal o animal, sobre la que actúa el agricultor, al control humano" (40).

Como hemos visto, los elementos integrantes del concepto de explotación, y particularmente del de carácter agrícola, se hallan correctamente formulados por la doctrina, en la que las ideas de una actividad racionalizada y técnicamente organizada para la obtención de unos rendimientos es evidente. De ahí que la doctrina jurisprudencial del Tribunal Supremo se halle muy próxima al planteamiento efectuado.

En cualquier caso, creemos que la preocupación por el concepto de explotación es más importante de lo que en principio pudiera parecer, pues, en efecto, no se trata de la simple actualización del frui romano, sino que su elaboración es consecuencia obligada del principio de la escasez, lo que hace que se relacione de forma directa con una función dinámica de la propiedad y constituya el centro en torno al cual deba girar conceptualmente toda actividad agraria.

En Italia, aun teniendo una definición en su Código civil (41) de lo que se entiende por empresario agrícola, se ha puesto de manifiesto la necesidad de una definición más rigurosa de la explotación agrícola. Así, Aldo María Luchini ha señalado, acertadamente, que al "legislador no le interesa tanto qué bienes produzca el empresario agrícola cuanto el "modo" por medio del cual obtiene tales bienes» (42).

(38) Citado por Ballarfin Marcial, Derecho..., op. cit., pág. 82.

(39) Derecho..., op. cit., págs. 266 y 267.

(40) «Para una construcción de los conceptos...», op. cit., pág. 113.

(41) Según el artículo 2.135 del citado Código, es empresario agrícola quien desarrolla una actividad tendente al cultivo del fundo, a la actividad forestal, a la crianza del ganado y a las actividades conexas.

(42) «La empresa agrícola en los sistemas de previsión social y tributarios», en Jornadas Italo-Españolas de Derecho Agrario, Salamanca-Valladolid, 1976, pág. 533. 
También desde el punto de vista tributario se ha intentado analizar el concepto de explotación —especialmente la agrícola-, para lo cual se ha acudido a distintos textos, aunque nunca a la Ley de Régimen local. Su apreciación ha venido configurada en función del tributo de que se tratase (43), por lo que su interés a efectos generales es muy discutible, siendo la más interesante la que se contiene en la legislación sobre la Contribución territorial rústica (44).

Debemos hacer referencia a la Ley de 12 de enero de 1973 reguladora de la reforma y desarrollo agrario. Se trata de la disposición más importante y más amplia (45) promulgada sobre la materia agraria y que ha otorgado una notable relevancia a la función social de la propiedad de fincas rústicas (46). Pues bien, este texto, aunque contiene frecuentísimas referencias a las "explotaciones» (47), tampoco las ha definido. Sin embargo, conviene destacar que en algunos preceptos de dicha Ley se hace referencia a la rentabilidad de las explotaciones, como si - aun sin decirlo- constituyese un elemento implícito de las mismas (48).

Finalmente, por nuestra parte, y a efectos del arbitrio sobre el incremento del valor de los terrenos, creemos poder definir la explotación como una actividad productiva o extractiva, económica $y$ técnicamente organizada, y que en relación al devengo del arbitrio

(43) Pueden verse los siguientes trabajos: Cortés Domf́nguez, Matías, «El concepto de explotación agrícola en la Ley de Reforma Tributaria de 11 de junio de 1964", en Revista de Derecho Mercantil, julio-septiembre, núm. 97, 1965, págs. 59-76. Este artículo se refiere a la contribución territorial rústica y pecuaria y particularmente al examen de las presunciones que la citada Ley supone sobre esta materia. En relación al mismo tributo, GARcfa AÑoveros, Jaime, "Explotación agrícola y contribución territorial", en Revista de Derecho Financiero y Hacienda Pública, julio-agosto, 1967, págs. 554 y sigs. GonZÁleZ SÁNCHEZ, M., "Aspectos tributarios de la productividad agraria (fincas mejorables) en el ordenamiento español", en Jornadas Italo-Españolas..., op. cit., págs. 140-150, que se refiere a las fincas mejorables; en la misma obra, LUNA SERRANo, Agustín, "Limitaciones al derecho...", op. cit., especialmente notas de la página 540; MonToBbio Jover, Juan Manuel, "La unidad de explotación agraria a efectos tributarios», en Revista Juridica de Cataluña, enero-marzo, núm. 1, 1976, págs. 201-210. Este artículo presta la atención a los aspectos relacionados con la cuota fija y cuota proporcional en la contribución territorial rústica y pecuaria.

(44) Vid. pág. 803.

(45) Contiene 290 artículos, 9 Disposiciones finales, 15 Disposiciones transitorias y una extensa y completa Disposición final derogatoria.

(46) Vid. especialmente el artículo $2 .^{\circ}$.

(47) Entre otros preceptos pueden citarse los siguientes: artículo 2., 1, b); artículo $3 .^{\circ}$, b); artículo $50^{\circ}, 1$, b); artículo 30,1, c); artículo 97,1, d) y h); artículo 110; artículo 128; artículo 129, 1; artículo 132, a) y c); artículo 140, 2; artículo 157, 2; artículo 173, c); artículo 251, 1, c); artículo 252, 2, y artículo 270.

(48) A título puramente indicativo citamos los siguientes artículos: $2 .^{\circ}, 1$, b); $43,2 ; 173, \mathrm{c}) ; 251,1, \mathrm{c}) ; 270$, y 271, a). 
sea: anterior, permanente, efectiva, actual, principal, con sustantividad propia y ánimo de obtener un lucro que represente una rentabilidad razonable (49).

\section{MANTENIMIENTO DE LA INDETERMINACION LEGAL DEL CONCEPTO. POSIBLES PROPUESTAS}

De todo lo expuesto llegamos a la conclusión de que el concepto de "explotación» en la forma en que viene referido en los textos citados, y muy especialmente en el Real Decreto de 30 de diciembre de 1976, mantiene con rigurosa plenitud su imprecisión. Por tanto, los problemas seguirán planteándose en la misma forma, igual motivación, y consecuentemente serán objeto de una parecida solución, obligando al Tribunal Supremo a llevar a cabo un notable esfuerzo interpretativo.

Si se comparan las actuales normas (que han mejorado -como ya hemos dicho al principio del trabajo- tan sólo en clarificar la sujeción de los incrementos de valor que se produzcan como consecuencia de transmisiones de terrenos que tengan la condición de urbanos, urbanizables o vayan adquiriendo esta condición) con la normativa que contenía el Estatuto municipal de 1924, nos daremos cuenta que en este aspecto dicho texto era mucho más realista que los que le han seguido, pues poseía criterios más significativos. Debe tenerse presente, por otra parte, que el Estatuto, dentro del planteamiento que hacía de la fiscalidad municipal, regulaba también el arbitrio sobre los terrenos incultos que se conjugaba debidamente con el arbitrio sobre el incremento del valor de los terrenos (50).

Con la publicación del Real Decreto al que nos hemos venido refiriendo, se ha perdido una nueva oportunidad para una modificación más decisiva en orden a la delimitación del ámbito del hecho

(49) Rebés SolÉ, José-Enrique, «Evolució...», op. cit., pág. 228.

(50) El artículo 409 establecía: "Serán objeto del arbitrio los terrenos que, no teniendo la consideración de solares a tenor de lo prescrito en el número $30^{\circ} \mathrm{del}$ artículo 386 de esta Ley, y siendo técnica y económicamente susceptibles de explotación agrícola, forestal o ganadera, no fueran de hecho objeto de aprovechamiento o lo fueran de modo notoriamente insuficiente atendidas aquellas posibilidades"; y en el párrafo siguiente daba unas normas para determinar cuándo debía de entenderse que el aprovechamiento era notoriamente insuficiente. Cuán diferente era esta regulación, que permitía mayores posibilidades interpretativas. 
imponible del arbitrio sobre el incremento del valor de los terrenos. En este sentido las alternativas podían haber sido varias:

1..$^{a} \quad$ Plena incorporación al texto legal de la orientación señalada por el Tribunal Supremo relativa al criterio proporcional.

2. ${ }^{2} \quad$ Exclusión, simplemente, de todos aquellos supuestos en los que el valor del terreno fuese el que corresponde a un terreno urbano y no agrícola. Con lo cual el ámbito de sujeción quedaría sustancialmente ampliado, reduciéndose numerosas cuestiones.

3. Introducción en la norma de una definición del concepto de explotación.

4. ${ }^{\text {a }}$ Cabría incluso otra posibilidad, cual es la supresión total de la afectación a explotaciones agrícolas, forestales, ganaderas o mineras, como elemento determinante de la no sujeción al arbitrio. Facultándose, en este caso, la correspondiente medida correctora por la vía de las mejoras (a base de deducirlas, como se contemplaba en el artículo 512 de la Ley de Régimen local, texto de 1955, o por medio de incrementar el valor inicial según el artículo 94.2 del Real Decreto vigente).

Sin embargo, esta última alternativa tiene una dificultad de tipo teórico, pues no parece congruente con el objeto y finalidad del arbitrio, que es la de gravar incrementos de valor inmerecidos, perjudicándose además todas aquellas explotaciones agrarias, que siguen siendo muchas.

\section{CONCLUSIONES}

Primera. Las afectaciones a explotaciones agrícolas, forestales, ganaderas o mineras no constituyen una excepción al arbitrio, y sí un supuesto de no sujeción al ser una delimitación del ámbito material de sujeción al mismo.

Segunda. El Tribunal Supremo ha seguido, para determinar lo que se entiende por "explotación», un criterio inicialmente vacilante, para luego establecer un criterio reiterado y fundado al exigir una rentabilidad proporcional.

Tercera. La interpretación actual que lleva a cabo el Tribunal Supremo se halla de acuerdo con el fundamento del arbitrio, al so- 
meter al mismo incrementos de valor inmerecidos -que de otra manera quedarían al margen del arbitrio-, sin que ello entrañe violencia de los principios de legalidad.

Cuarta. Se aprecia en nuestro ordenamiento la ausencia de una definición del concepto de «explotación» que tenga validez general. Sin embargo, es bastante aproximada la referencia que se contiene en las normas relativas a la Contribución territorial rústica.

Quinta. En concreto, el concepto de explotación a los efectos del arbitrio sobre el incremento del valor de los terrenos tiene un carácter de concepto jurídico indeterminado, lo que ha acusado el Tribunal Supremo. Esta imprecisión se ha mantenido con la misma intensidad desde la creación del arbitrio hasta la actualidad, con la única y breve salvedad contenida en el Estatuto de 1924.

Sexta. La regulación contenida en el Real Decreto de 30 de diciembre de 1976, hoy vigente, solamente ha reducido legalmente el ámbito de los supuestos de no sujeción, al ampliar el concepto de solar a todos los terrenos: urbanos, urbanizables, programados o que adquieran esta denominación de acuerdo con la Ley del Suelo, con lo que se ha producido la lógica congruencia entre las dos legislaciones.

Séptima. Sin embargo, se ha perdido la oportunidad de haberse procedido a una ambiciosa y realista modificación del punto que hemos comentado, cuya actualización sigue siendo una necesidad, lo que se podía haber conseguido con la incorporación de alguna de las formas indicadas al final de este trabajo.

Octava. Para terminar, citamos el concepto de "explotación» a efectos del arbitrio sobre el incremento del valor de los terrenos, que hemos efectuado en otro lugar (51), y que la definimos como «una actividad productiva o extractiva, económica y técnicamente organizada, y que en relación al devengo del arbitrio sea: anterior, permanente, efectiva, actual, principal, con sustantividad propia y ánimo de obtener un lucro que represente una rentabilidad razonable».

(51) Vid. nota 49. 
REVL-1977, núm. . REBES SOLE, JOSE-ENRIQUE. EL CONCEPTO DE EXPLOTACION COMO UNO ...

REVISTA

DE

Pren

( DE LA

VIDA LOCAL

\section{CRONICAS}

REVL-1977, núm. . REBES SOLE, JOSE-ENRIQUE. EL CONCEPTO DE EXPLOTACION COMO UNO ... 
REVL-1977, núm. . REBES SOLE, JOSE-ENRIQUE. EL CONCEPTO DE EXPLOTACION COMO UNO ... REVL-1977, núm. . REBES SOLE, JOSE-ENRIQUE. EL CONCEPTO DE EXPLOTACION COMO UNO ... 